\title{
Surgery vs. radiotherapy in localized prostate cancer. Which is best?
}

\author{
Stefan Welz ${ }^{1}$, Maximilian Nyazi ${ }^{1}$, Claus Belka² and Ute Ganswindt*2
}

Address: ${ }^{1}$ Department of Radiation Oncology, Eberhard-Karls-University, Hoppe-Seyler-Str. 3, 72076 Tübingen, Germany and ${ }^{2}$ Department of Radiation Oncology, Ludwig-Maximilians-University, Marchionini-Str. 15, 81377 Munich, Germany

Email: Stefan Welz - stefan.welz@med.uni-tuebingen.de; Maximilian Nyazi - maxi@niyazi.de; Claus Belka - claus.belka@uni-tuebingen.de; Ute Ganswindt* - ute-ganswindt@med.uni-tuebingen.de

* Corresponding author

Published: 7 September 2008

Radiation Oncology 2008, 3:23 doi:10.1 186/1748-7/7X-3-23

This article is available from: http://www.ro-journal.com/content/3/I/23

(C) 2008 Welz et al; licensee BioMed Central Ltd.

This is an Open Access article distributed under the terms of the Creative Commons Attribution License (http://creativecommons.org/licenses/by/2.0), which permits unrestricted use, distribution, and reproduction in any medium, provided the original work is properly cited.
Received: 25 January 2008

Accepted: 7 September 2008

\begin{abstract}
Surgery and radiotherapy are currently accepted alternatives for the treatment of localized prostate cancer. In the absence of relevant randomized trials no decision regarding the superiority of any of the given approaches can be made. Up to now several cohort-based approaches indicate similar outcomes for both treatments. Based on a new population based approach, Merglen and co-workers recently concluded that surgery would offer the best chance of long-term control in terms of 10-year survival for TI-T3 prostate cancer patients. Unfortunately the strength of this trial is limited by several shortcomings. Most importantly, issues of radiation dosage have not been taken into account. In addition, several relevant parameters including Gleason score and PSA are not well balanced between the arms and the assignment to arbitrary risk groups does not reflect the real biological behaviour. Thus, the data provided do not support the strong conclusion issued by the authors. Based on the data available, surgery and radiotherapy still have to be considered as equally effective.
\end{abstract}

\section{Commentary}

Despite an intense debate over the last decades, there is no agreement today on the treatment of choice for localized prostate cancer. This is mainly due to the absence of large randomized trials comparing radical prostatectomy and radiation-based approaches. Therefore, clinicians have to rely on retrospective and population-based trials which, due to their nature, comprise a considerable risk of misinterpretation and must be analyzed very carefully [1].

In this regard, a Swiss group performed a population based analysis on treatment outcome after radiotherapy or surgery for prostate cancer in the Geneva region [2], which is, unfortunately, subject to an array of methodological pitfalls and misinterpretations.
This trial is a retrospective observational cohort study on 844 T1-3 prostate cancer patients documented in the Geneva Cancer Registry with a treatment period from 1989 to 1998.

The authors state, that the 5-year overall- and cancer-specific survival rates were almost identical for radiotherapy and prostatectomy but worse for the other treatment options. After ten years, the authors noted, that prostate cancer specific survival was inferior in radiotherapy-only patients when compared to surgery-only patients. No such difference was seen when surgery-only was compared to radiotherapy plus hormonal ablation. Watchful waiting and hormonal treatment only were found to have inferior outcomes. 
These conclusions are based on the endpoint "mortality from prostate cancer". Yet, the authors fail to provide a definition for this endpoint, which itself is difficult to assess. It has been shown, that the cause of death in patients with prostate cancer is easily misattributed [3]. Since this aspect, concerning the most important endpoint of the study, is totally ignored by Merglen et al, misinterpretation of the data is due to happen.

Additionally, there are several further shortcomings that limit the value of the current study, most of which concern confounding variables:

First, the Gleason score is missing in $15 \%$ of the radiotherapy patients and in only $3 \%$ of the surgical patients. Furthermore, the grouping of patients was not based on the Gleason score only, but on a mixture of Gleason score and grading. The result is, that patients with a Gleason of 7 are analyzed in the same group as patients with a Gleason of 10 , despite the fact that these scores represent distinct risk populations [4]. Another important predictor for the outcome after treatment is the initial PSA level. Again, there is a severe imbalance with $37 \%$ of the radiotherapy patients having PSA levels higher than $20 \mathrm{ng} / \mathrm{ml}$ whereas only $27 \%$ of the surgical patients had such PSA values. Moreover, there was a difference of $8 \%$ in patients with a PSA level above $30 \mathrm{ng} / \mathrm{ml}$ in favour of the surgical group. Next, there is the issue of the lymph node status: There is no hint, on how patients in the radiotherapy group have been staged. Resected patients are prone to have had pathological staging, whereas radiotherapy patients probably had computed tomography, which is known to be unreliable in this regard $[5,6]$. Thus, another bias is introduced.

The authors employed a Cox-regression model to adjust for given imbalances. This model should be able to control for imbalanced confounding factors if the influence of these factors is equally distributed in all subgroups. Although the used Cox model is an adequate statistical tool, it is doubtful whether statistical tools may be of any use to make up for inadequate grouping of risk factors (Gleason) or for a possible systematic clinical understaging of certain patient collectives ( $\mathrm{N}$-status in radiotherapy patients). At no point in their paper the authors indicated possible weaknesses of this approach.

Last but not least, the authors completely neglected the importance of adequate dosage for the outcome of radiation-based treatment approaches [7-9]. In the last 15 years, advances in technical equipment allowed an escalation of the prescribed dose to the level which is standard nowadays. Since the trial by Merglen et al. was done in the late eighties, it is likely that non-optimal radiation doses were applied. Yet, the authors do not provide any data on this aspect. Considering, that study patients with radio- therapy and hormonal ablation show a comparable outcome to surgical patients, the reason could be, that hormonal therapy at least partially compensated for underdosage [10].

In conclusion, the statement issued by Merglen and coworkers that "surgery offers the best chance of long-term prostate-cancer-specific survival in particular for younger patients and patients with poorly differentiated tumours" is not supported by the data presented in their paper. Most of the obvious problems including the effects of radiation dose, clinical vs. pathological staging as well as the attribution of causes of death are not discussed by the authors. The same is true for critical aspects on the discussed issue in the papers that were already mentioned. Additionally, there are data indicating an equivalence of radical prostatectomy and radiotherapy, provided, that an adequate radiation dose is prescribed [11-16], a fact, which is neglected in the discussion.

Thus, despite the fact that observational studies are necessary to evaluate the efficacy of surgery vs. radiotherapy in prostate cancer, the paper by Merglen et al. does not add valid information. In addition, we would be highly reluctant to use these data for patient counselling as suggested by the authors "Until clinical trials provide conclusive evidence, physicians and patients should be informed of these results and their limitations".

\section{Competing interests}

The authors declare that they have no competing interests.

\section{Authors' contributions}

SW and UG did the literature research and drafted the manuscript, UG and MN revised the manuscript, $\mathrm{CB}$ and UG conceived the article and revised it. All authors read and approved the final manuscript.

\section{References}

I. Barry MJ, Albertsen PC, Bagshaw MA, Blute ML, Cox R, Middleton RG, Gleason DF, Zincke H, Bergstralh EJ, Jacobsen SJ: Outcomes for men with clinically nonmetastatic prostate carcinoma managed with radical prostactectomy, external beam radiotherapy, or expectant management: a retrospective analysis. Cancer 200 I, 9 I ( I 2):2302-14.

2. Merglen A, Schmidlin F, Fioretta G, Verkooijen HM, Rapiti E, Zanetti R, Miralbell R, Bouchardy C: Short- and long-term mortality with localized prostate cancer. Arch Intern Med 2007, I 67( I 8): 1944-50.

3. Newschaffer CJ, Otani K, McDonald MK, Penberthy LT: Causes of death in elderly prostate cancer patients and in a comparison nonprostate cancer cohort. I Natl Cancer Inst 2000, 92(8):6I3-2I. Comment in: J Natl Cancer Inst 200I, 93(5): 397-8.

4. Partin AW, Mangold LA, Lamm DM, Walsh PC, Epstein JI, Pearson JD: Contemporary update of prostate cancer staging nomograms (Partin Tables) for the new millennium. Urology 200 I, 58(6):843-8.

5. Borley N, Fabrin K, Sriprasad S, Mondaini N, Thompson P, Muir G Poulsen J: Laparoscopic pelvic lymph node dissection allows significantly more accurate staging in "high-risk" prostate cancer compared to MRI or CT. Scand J Urol Nephrol 2003, 37(5):382-6. 
6. Flanigan RC, McKay TC, Olson M, Shankey TV, Pyle J, Waters WB: Limited efficacy of preoperative computed tomographic scanning for the evaluation of lymph node metastasis in patients before radical prostatectomy. Urology 1996, 48(3):428-32.

7. Ganswindt U, Paulsen F, Anastasiadis AG, Stenzl A, Bamberg M, Belka C: 70 Gy or more: which dose for which prostate cancer? J Cancer Res Clin Oncol 2005, I 3 I(7):407-19.

8. Pollack A, Zagars GK, Starkschall G, Antolak JA, Lee J], Huang E, von Eschenbach AC, Kuban DA, Rosen I: Prostate cancer radiation dose response: results of the M. D. Anderson phase III randomized trial. Int J Radiat Oncol Biol Phy 2002, 53(5): 1097-I05.

9. Zelefsky MJ, Fuks Z, Hunt M, Lee HJ, Lombardi D, Ling CC, Reuter VE, Venkatraman ES, Leibel SA: High dose radiation delivered by intensity modulated conformal radiotherapy improves the outcome of localized prostate cancer. J Urol 200I, 166(3):876-8I.

10. Bolla M, Collette L, Blank L, Warde P, Dubois JB, Mirimanoff RO, Storme G, Bernier J, Kuten A, Sternberg C, Mattelaer J, Lopez Torecilla J, Pfeffer JR, Lino Cutajar C, Zurlo A, Pierart M: Long-term results with immediate androgen suppression and external irradiation in patients with locally advanced prostate cancer (an EORTC study): a phase III randomised trial. Lancet 2002, 360(9327): 103-6.

II. D'Amico AV, Whittington R, Malkowicz SB, Schultz D, Blank K, Broderick GA, Tomaszewski JE, Renshaw AA, Kaplan I, Beard CJ, Wein $A$ : Biochemical outcome after radical prostatectomy, external beam radiation therapy, or interstitial radiation therapy for clinically localized prostate cancer. JAMA 1998, 280(II):969-74.

12. D'Amico AV, Whittington R, Malkowicz SB, Cote K, Loffredo M, Schultz D, Chen MH, Tomaszewski JE, Renshaw AA, Wein A, Richie JP: Biochemical outcome after radical prostatectomy or external beam radiation therapy for patients with clinically localized prostate carcinoma in the prostate specific antigen era. Cancer 2002, 95(2):28I-6.

13. Kupelian PA, Elshaikh M, Reddy CA, Zippe C, Klein EA: Comparison of the efficacy of local therapies for localized prostate cancer in the prostate-specific antigen era: a large single-institution experience with radical prostatectomy and external-beam radiotherapy. J Clin Oncol 2002, 20(16):3376-85.

14. Kupelian PA, Potters L, Khuntia D, Ciezki JP, Reddy CA, Reuther AM, Carlson TP, Klein EA: Radical prostatectomy, external beam radiotherapy $<72 \mathrm{~Gy}$, external beam radiotherapy $>$ or $=\mathbf{7 2}$ Gy, permanent seed implantation, or combined seeds/external beam radiotherapy for stage TI-T2 prostate cancer. Int $J$ Radiat Oncol Biol Phy 2004, 58(I):25-33.

15. Fletcher SG, Mills SE, Smolkin ME, Theodorescu D: Case-matched comparison of contemporary radiation therapy to surgery in patients with locally advanced prostate cancer. Int $J$ Radiat Oncol Biol Phys 2006, 66(4): 1092-9.

16. Akakura K, Suzuki H, Ichikawa T, Fujimoto $H$, Maeda O, Usami M, Hirano D, Takimoto Y, Kamoto T, Ogawa O, Sumiyoshi Y, Shimazak J, Kakizoe T, Japanese Study Group for Locally Advanced Prostate Cancer: A randomized trial comparing radical prostatectomy plus endocrine therapy versus external beam radiotherapy plus endocrine therapy for locally advanced prostate cancer: results at median follow-up of 102 months. Jpn J Clin Oncol 2006, 36( I 2):789-93.
Publish with Biomed Central and every scientist can read your work free of charge

"BioMed Central will be the most significant development for disseminating the results of biomedical research in our lifetime. "

Sir Paul Nurse, Cancer Research UK

Your research papers will be:

- available free of charge to the entire biomedical community

- peer reviewed and published immediately upon acceptance

- cited in PubMed and archived on PubMed Central

- yours - you keep the copyright

Submit your manuscript here:

http://www.biomedcentral.com/info/publishing_adv.asp
BioMedcentral 